\title{
Effects of calcination temperature on microstructure and superconducting properties of Y123 ceramic prepared using thermal treatment method
}

\begin{abstract}
Thermal treatment method was employed to produce $\mathrm{YBa}_{2} \mathrm{Cu}_{3} \mathrm{O}_{x}$ superconductor ceramic. The effects of calcination temperature at $850{ }^{\circ} \mathrm{C}$, set $\mathrm{A}$, and $910{ }^{\circ} \mathrm{C}$, set $\mathrm{B}$, for $24 \mathrm{~h}$ followed by sintering at 930,950 and $980{ }^{\circ} \mathrm{C}$, were investigate using X-ray diffraction (XRD), scanning electron microscope (SEM) and four point probe measurement. The orthorhombic structure appears after calcination at 850 and $910{ }^{\circ} \mathrm{C}$ beside small amount of impurity phase such as $\mathrm{Y}_{2} \mathrm{BaCuO}_{5}(\mathrm{Y} 211)$. The samples exhibited metallic behaviour and the critical temperature, $T_{C(R=0)}$, increases with increasing sintering temperature. The $T_{C(R=0)}$ of samples calcined at $910{ }^{\circ} \mathrm{C}$ is higher than that of sample calcined at $850{ }^{\circ} \mathrm{C}$. The highest $T_{C(R=0)}, 87 \mathrm{~K}$, was found for sample sintered at $980{ }^{\circ} \mathrm{C}$ of set B. An increase in grain size and homogeneity was observed as the sintering temperature increases. The set B sample sintered at $980{ }^{\circ} \mathrm{C}$ showed compact grains, which could result in the highest $T_{c(R=0) \text {. }}$
\end{abstract}

Keyword: YBa2Cu3Ox; Thermal treatment; X-ray diffraction; Orthorhombic; Critical temperature 